\title{
Leprosy: Before And After Elimination From Nepal
}

\author{
Jha AK \\ Department of Dermatology \\ Nepal Medical College, Kathmandul
}

Leprosy is still considered as a serious public health concern with social stigma in a developing country like Nepal. Howsoever leprosy was declared eliminated from Nepal by the government of Nepal in 2009. ${ }^{1}$ The globally registered prevalence of leprosy at the beginning of 2011 stood at 192,246 cases $(0.34 / 10,000)$ with 113,750 cases $(0.64 / 10,000)$ from the South-East Asia and the number of new cases detected globally during 2010 was 228,474 out of which $68.4 \%$ belonged to the South-East Asia. ${ }^{2}$

In 1960 in Nepal leprosy survey was done in collaboration with World Health Organization(WHO). In 1966, pilot project was launched to control leprosy with Dapsone mono therapy with an estimated number of 1,00,000 leprosy cases. ${ }^{3}$ The most important development in the leprosy control program has been the introduction of Multidrug Therapy (MDT) in 1982. In 1996, the coverage with MDT reached $100 \%$ and the prevalence gradually declined from $2.2 / 10,000$ population in 2005 to $0.79 / 10,000$ population in July 2011. ${ }^{4}$ However, the prevalence is uneven in different parts of the country which is higher in Tarai districts, $1-2 / 10,000$ population, and more than $83 \%$ of cases found in Nepal are from those districts. This means that concerted effort to manage leprosy in Tarai should be continued even though it is declared eliminated nationally. Even though there has been significant reduction in leprosy cases in Nepal, new leprosy cases will keep coming as disease transmission is still a continuing process in the community. The number of new patients recorded at Anandaban Hospital, the largest leprosy hospital in Nepal, for the past few years is 119(2007), 93(2008), 105(2009), 127(2010) and 136(2011). Leprosy was eliminated in the year 2005 in neighboring India. However, the numbers of leprosy patients presenting to dermatologists in both private practice and teaching hospitals has been increasing in the post elimination phase. ${ }^{5-7}$ Looking at these figures we can see that there is a tendency to have increased number of cases in post elimination phase as various national and international organizations including WHO were very active in the pre elimination phase looking after the leprosy issue, but are not vigilant as the disease is considered not to be a serious problem anymore and NGOs and INGOs working against leprosy during pre elimination phase have started winding up in the post elimination phase.

The involvement of concerned specialists and clinicians in these projects seem to be very less in Nepal in both pre and post elimination phase which could be a reason for the increase in the number of leprosy cases in the post elimination phase. Hence, constant vigilance is required with the active involvement of concerned specialist even after elimination to see that the disease does not reappear in the community. Screening of close contacts of new Paucibacillary (PB) \& Multibacillary (MB) patients inside and outside of the household could be one of the measures which could help in detecting and treating the hidden cases so that the prevalence can be further reduced in the years to come. The responsibility of the concerned specialists and clinicians has increased in post elimination phase as the role of public health sector in control the disease gradually wither off. ${ }^{8,9}$ There are still several important issues regarding leprosy to be considered to achieve the real elimination of leprosy from Nepal. Among several vital issues the diagnostic criteria and treatment of leprosy seems to be the important issues to be revisited. There are controversies with regard to the WHO guidelines on leprosy diagnostic criteria and the text book criteria in medical institutions. This has created some confusion between the specialists and public health workers and paramedical staffs involved in leprosy management and may have serious impact leading to misdiagnosis, insufficient treatment and increase in MB leprosy cases. This may be the reason for lower number of patients with MB leprosy in the national data compared to the data received from leprosy hospitals and other medical colleges/ hospitals. The Government and the medical institutions should work it out as soon as possible to achieve the real elimination of leprosy from the country.

The national target for next five years is to reduce disability grade 2 (i.e. visible disability) by $35 \%$, new case detection rate by $25 \%$ and prevalence rate by $35 \%$, in comparison to $2010 .{ }^{10}$ To prevent the development of disability in leprosy patients, early diagnosis and treatment of leprosy is important. Mycobacterium leprae residues can remain for many years after MDT while patients are still at risk for lepra reaction for many years which may also lead to development of disability due to nerve injury in these patients. Therefore Primary 
Health Care (PHC) medical officers should be trained not only about diagnosis but also to identify possible development of lepra reaction so that they can refer such cases to the higher centers. And for patients who have already developed disabilities which are irreversible, rehabilitation is of utmost importance. The rehabilitation should be comprehensive involving legal, social, religious and medical and occupational aspects and should be carried out from the centre to the grass root level. Comprehensive community level approach alone can reduce and possibly eliminate not only leprosy but also the stigma attached with it leading to restoration of self esteem in these patients.

\section{REFERENCES}

1. Weekly epidemiological record. World Health Organization. 27 Aug 2010:85;337-48.

2. Weekly epidemiological record. World Health Organization. Sept 2011:86;389-400.

3. Leprosy Control Division, Department of Health Services. His Majesty's Government of Nepal Ministry of Health and Population. Annual report 2062/2063 (2005/2006), Kathmandu: Leprosy Control Division; 2006 Nov 7:29.

4. Jain MC. Leprosy Scenario in Nepal. J Nepal Med Assoc. 2008;47(172):259-63.

5. Jain A. Current status of leprosy as seen in a tertiary care hospital in north India. Indian Journal of Medical Research 2012;135:3:439-440.

6. Singal A, Sonthalia S, Pandhi D. Childhood leprosy in a tertiary-care hospital in Delhi, India: a reappraisal in the post-elimination era. Lepr Rev 2011 Sep;82(3):259-69

7. Mehta B, Nayak C, Savant S, Amladi S. Leprosy in the era of integration. Indian J Dermatol Venereol Leprol 2009; 5:2: $190-1$.

8. Pandey A. Role of dermatologist in leprosy elimination and post elimination era. Lepra Review 2007;78:26-29.

9. Oliveira ML, Penna GO, Telhari S.Role of dermatologists in leprosy elimination and post-elimination era: the Brazilian contribution. Lepr Rev 2007 Mar;78(1):17-21.

10. Leprosy Control Division, Ministry of Health and Population, Government of Nepal. Current situation of leprosy and strategies. IXth SODVELONCON ( IXth National Conference of Society of Dermatologists, Venereologists \& Leprologists of Nepal); 30- 31March. 2012 